\title{
LAS NUEVAS TECNOLOGÍAS DE LA INFORMACIÓN Y DE LA COMUNICACIÓN (NTIC) EN LA EDUCACIÓN UNIVERSITARIA. ${ }^{1}$
}

\author{
Alicia Gurdián Fernández²
}

\begin{abstract}
Con cuánta frecuencia imaginamos ..., ¿cuántas personas trabajarán en sus casas, irán a la escuela, leerán libros sin páginas o realizarán sus compras utilizando las autopistas de la información en el año 2010, o en el 2015 o en el 2020?
\end{abstract}

Esta conferencia tiene como punto de partida tres supuestos muy generales que tienen la finalidad de invitar a su discusión y análisis reflexivo.

\section{Estamos viviendo una nueva revolución educativa.}

Tanto en el contexto en que funciona la escuela, como en sus fines, están siendo transformados drásticamente por fuerzas que se hallan fuera del control de la comunidad educativa, pero a pesar de ello sus sobre ésta son inevitables. La escuela quiéralo o no está siendo forzada a cambiar. Es urgente que la escuela asuma el rol protagónico que históricamente y políticamente le corresponde asumir.

\section{En la base de esa transformación que se le impone a la escuela se encuentra un} nuevo paradigma tecnológico.

La revolución que apuntamos es una revolución tanto tecnológica como comunicativa. No se trata únicamente de que el conocimiento y la información jueguen un papel económico y social relevante.

Lo diferente o distintivo es que las nuevas tecnologías de la información y la comunicación, en el ámbito educativo, son "procesos para ser desarrollados" y no "herramientas para ser aplicadas".

\footnotetext{
${ }^{1}$ Notas para propiciar una discusión cibernética: Videoconferencia organizada por el Lic. Gustavo Galland, en Argentina, y realizada el 28 de octubre de 2000 con la Facultad Regional Haedo de la Universidad Tecnológica Nacional de Argentina. Sin el apoyo incondicional del Centro Nacional de Alta Tecnología (CENAT) de CONARE de Costa Rica no hubiese sido posible realizar esta actividad.

${ }^{2}$ Catedrática investigadora y Directora del Instituto de Investigaciones para el Mejoramiento de la Educación Costarricense, IIMEC de la Facultad de Educación de la Universidad de Costa Rica. Coordinadora del Proyecto Red ProEducación.
} 
En consecuencia las y los profesores universitarios tenemos que enfrentar el reto para tomar control sobre dichos procesos y crear, imaginar, inventar o producir nuevas ideas, bienes, servicios y aplicaciones para sistematizar o desarrollar procesos existentes o inéditos mediante la aplicación de las NTIC en los procesos de aprendizaje y enseñanza en las aulas universitarias y fuera de ellas.

\section{Vivimos dentro de una cultura mediática, a partir de la cual se ha empezado a generar una cultura cibernética: un verdadero sistema neurológico mundial que indiscutiblemente repercute en nuestra manera de ser, aprender, sentir, enseñar y actuar queramos o no admitirlo.}

Ahora bien, ¿Cuáles son las implicaciones que impone el asumir los tres supuestos anteriores? Es de vital importancia que nos arriesguemos a enfrentar este nuevo reto, por lo que me atreveré a lanzar unas ideas al respecto.

En primer lugar, la utilización de las nuevas tecnologías de la información y la comunicación (NTIC) en la educación es una decisión no sólo financiera, sino también social y política $y$, como tal, es prioritario que se sitúe en el centro de las preocupaciones de los gobiernos de la región, de las instituciones educativas, y de las organizaciones de la sociedad civil, entre otros.

En segundo lugar, la amplia expansión de redes electrónicas no implica la concentración de conciencias y voluntades. Pero sin lugar a dudas las consecuencias de esta expansión técnica, material y simbólica de las NTIC marca de manera decisiva la vida contemporánea.

En tercer lugar, a partir de dicha expansión se adivina: la aparición y configuración de nuevas disciplinas, de nuevas técnicas del saber y del aprender, nuevas técnicas del hacer y del sentir. Se adivina también la aparición de una nueva pragmática del lenguaje, de nuevos géneros narrativos y nuevos de modos de relatar.

Esta expansión también representa una transformación de las relaciones interpersonales, nuevas formas de percibir el tiempo y el espacio. Esta expansión de igual forma representa una redistribución diferente de los espacios de la cotidianidad.

En cuarto lugar, el riesgo principal que corremos consiste en la creación de nuevas rupturas y desequilibrios, ya sea entre las distintas sociedades -entre las más ricas y las más pobres- o dentro de cada sociedad en particular, porque es eminente el peligro de crear desigualdades entre quienes tengan acceso, produzcan y dominen las NTIC y quienes no tengan esa posibilidad. En conclusión, las NTIC crean nuevas formas de socialización e incluso nuevas definiciones de la identidad individual y colectiva. Lo anterior conduce a la siguiente interrogante: ¿Cómo utilizar el espacio cibernético para asegurarnos una re-distribución justa y solidaria del conocimiento?

En quinto lugar, la utilización crítica de la NTIC representa una transformación en el campo educativo formal e informal de los siguientes aspectos, entre otros:

- De los modelos de pensamiento en la estructura del conocimiento y en los procesos

- de enseñanza y aprendizaje.

- En la re-estructuración de las formas tradicionales de organización, división y especialización del conocimiento. 
- Las nuevas formas de apropiación del conocimiento producirán cambios en las técnicas pedagógicas y didácticas.

- De las nuevas formas de circulación del conocimiento entre la educación formal e informal.

- En la búsqueda de la información y la forma para seleccionarla y relacionarla críticamente.

- En el desplazamiento de un aprendizaje sincrónico hacia uno asincrónico.

- Una nueva relación entre las y los actores del proceso educativo.

- Una visión cogestionaria del proceso de formación.

- El desplazamiento del proceso de formación, espacial y temporalmente, definido hacia una educación permanente a lo largo de toda la vida y sin una dimensión espacialmente definida.

- La incorporación de nuevos conocimientos al ritmo que se producen.

- En la diversificación y el mejoramiento de las modalidades existentes de educación a distancia.

Considero oportuno introducir para la reflexión requerida y la discusión obligada las siguientes inquietudes, en el debate sobre la "actualización y formación" de las y los profesionales, así como de las y los profesores (as) universitarios en la actual coyuntura:

* ¿Cómo enfrentan cotidianamente las y los estudiantes y las y los profesores la incertidumbre de un presente que acumula los problemas del pasado y las exigencias del futuro?

* ¿Qué significa formar profesionales en la actual coyuntura?

* ¿Para qué y por qué estamos formando profesionales en las diferentes áreas del saber?

* ¿Qué problemas hay que enfrentar, qué nuevas estrategias es preciso diseñar y utilizar en un presente que puede suspenderse, colocarse entre paréntesis, o en los papeles pero no en la tarea cotidiana de las y los profesores universitarios?

* ¿Qué significa formar profesionales hoy para un futuro incierto y qué previsiones estamos tomando?

* ¿Cuáles son las competencias básicas, genéricas y específicas propias de las NTIC, que debe poseer una o un profesor universitario para lograr un desempeño profesional excelente, su ética y efectivo?

De estas preguntas se desprenden diversos problemas relacionados con la educación permanente de las y los profesores universitarios, de los cuales me interesa destacar dos de los más urgentes:

1. El primero se relaciona con las características de la actividad docente.

2. El segundo se relaciona con el papel de las (NTIC) en la práctica y formación de docentes universitarios. 

docente:

Del primero me interesa subrayar las siguientes características de la actividad

1.1 la multiplicidad de responsabilidades y tareas que supone el ser docente y el hacer docencia,

1.2 la variedad y desigualdad de los contextos en que se desempeñan dichas responsabilidades y tareas,

1.3 la complejidad tanto del acto pedagógico,

1.4 la complejidad de la construcción de la y el sujeto en situación pedagógica y

1.5 el compromiso personal y el posicionamiento ético que supone la tarea docente en la celeridad del mundo actual.

En relación con el segundo problema, relacionado con el papel de las NTIC en la práctica y educación permanente de las y los docentes universitarios.

Es pertinente tomar en consideración que ya no se está hablando de la exploración del espacio exterior, sino de volar en el ciberespacio y, en el mundo de la imaginación y en él, las y los docentes se convertirán en una generación de "pilotos de prueba".

Es posible pensar que con la interactividad penetrante de Internet, las computadoras y los programas de computación, cada vez más eficientes, la era de la información podría cambiar -rápidamente- a la era de la imaginación, un mundo en el que cualquier cosa que imaginemos puede ser rápidamente simulada y compartida en un mundo global a través de las tecnologías de los medios digitales. Esto nos lleva a otras interrogantes:

* ¿Cómo podemos visualizar el nuevo territorio que surge de la unión multimedia/Internet?

* ¿Cuál sería el modo natural de organizar los distintos tipos de información que participan en esta mezcla multimedia?

* ¿Cómo visualizar el escenario pedagógico de la unión multimedia/Internet?

En síntesis, ¿será válido afirmar que la historia de la comunicación educación, desde las palabras del cuentacuentos hasta las fantasías simuladas de Internet está aún por escribir?

Ahora bien, es preciso puntualizar y ubicar en el aquí y en el ahora el tema que nos ocupa, el de la introducción de las nuevas tecnologías de la información y de la comunicación (NTIC) en la educación universitaria. Las siguientes interrogantes le dan direccionalidad al proceso de reflexión que propiciamos en torno a esta temática.

* ¿Qué retos y desafíos ofrecen las NTIC a las políticas educativas universitarias que subyacen en los planes actuales y futuros de formación de profesionales y en los de actualización de docentes universitarios?

* ¿Cómo garantizar que la utilización de las NTIC en la práctica y en la actualización de profesores universitarios no promoverá la exclusión de amplios sectores de la población docente?

* ¿Cuál es el compromiso institucional y personal y cuál el posicionamiento ético que supone la tarea docente en la celeridad del mundo actual y ante las NTIC?

Para terminar introduzco esta reflexión final en la que me interesa destacar algunos de los aspectos más sobresalientes y relevantes. 
Los escenarios teóricos que, hasta hoy, se han producido sobre el futuro de la educación muestran que los cambios más importantes se producirán en el seno de las transacciones comunicativas y éstas constituyen el núcleo del proceso de aprendizaje.

Todo predice que se deberá recurrir a un enfoque centrado en el aula, en el proceso de aprendizaje y en consecuencia en la relación cotidiana que define la relación (mediación) pedagógica. Por lo que consecuentemente es preciso asumir la innovación como tarea clave en las aulas universitarias.

Las sociedades actuales tienden a ser, en mayor o menor medida, "sociedades de la información o del conocimiento", por lo que el desarrollo de las nuevas tecnologías de la información y la comunicación (NTIC) propicia un entorno cultural y educativo capaz de diversificar no sólo las fuentes del conocimiento y el saber, sino también de impulsar su redistribución. Sin embargo, la aplicación de las NTIC en la Educación Superior excede el marco de su simple utilización pedagógica y requiere una reflexión amplia y colectiva sobre el acceso al conocimiento, así como sobre la viabilidad de ubicar las NTIC en los contextos sociales, económicos y políticos apropiados y específicos para garantizar su democratización.

Vivimos un profundo proceso de transformación, donde aparecen nuevas formas de organización social, económica y política identificadas como: "sociedad de la información", "sociedad del conocimiento", "sociedad post-industrial", "tercera ola", "aldea global", "fábrica global", entre otras. Formas estas que suscitan diferentes análisis y priorizan diferentes aspectos sociales, culturales, políticos, económicos, éticos geográficos, geopolíticos, demográficos, lingüísticos y otros. Pero, más allá de las diferencias de perspectivas y enfoques, todo indica que nos enfrentamos con la conformación de una nueva estructura social. Los nuevos discursos anuncian procesos de transformación social, económica y política que alterarán todas las dimensiones de la vida social e individual. Una mirada a esta situación desde el punto de vista de la educación, permite apreciar el consenso que existe en reconocer que el conocimiento y la información constituyen los aspectos más importantes en la explicación de las nuevas formas de organización social y económica.

Acceder al espacio cibernético presenta un reto para la democracia, para la educación en general y para la Educación Superior en particular. Este reto supone crear mecanismos que permitan, a las y los actores sociales, tomar distancia con respecto a una sociedad mediática caracterizada tanto por lo efímero como por lo instantáneo. De igual forma, corresponde aportar los modos de socialización indispensables para una apropiación sana y crítica de los NTIC y sentar las bases para el ejercicio de una ciudadanía apropiada a las exigencias de nuestra época.

La existencia de procesos globales que trascienden grupos, clases sociales y naciones y que se sustenta en la hipótesis de la emergencia de una sociedad global todavía en construcción, proceso en el cual la educación, entendida como la actividad mediante la cual se produce y distribuye el conocimiento asume una importancia histórica inédita no sólo desde el punto de vista político-social, sino también de los contenidos de la socialización y su impacto en la apropiación inteligente del espacio cibernético.

El desequilibrio económico entre los países del Norte y los países del Sur debe ser tomado en consideración para la introducción de las NTIC en la educación, Costa Rica y, la Universidad de Costa Rica en particular, cuentan con la materia prima básica - conocimiento y capacidad investigativa - para incursionar en este campo. Sin embargo, además de inversión en equipo también se requiere la formación y actualización del recurso humano que se encargará de aplicar y desarrollar las NTIC para que se utilicen en las aulas universitarias, ojalá mediante la utilización de ellas mismas en dichos procesos. No olvidemos que una de las mejores formas de aprender es haciendo. En síntesis, saber es ser, pensar y hacer. 
El amplio horizonte que se abre con la sociedad global, en términos de integración y fragmentación, abre nuevas posibilidades para interpretar el presente, así como para releer el pasado e imaginar el futuro de la educación. Este horizonte también invita a la reflexión e imaginación para analizar qué está sucediendo en el mundo en general y, en el universitario en particular, para interpretar realidades no codificadas y arriesgarnos a adivinar sorpresas inimaginadas. El reto es atractivo para la Universidad, pero la respuesta no puede hacerse esperar. 